\title{
FLAVONOIDS OF THE LEAVES OF Evonymus japonicus
}

\author{
N. V. Sergeeva and A. L. Shinkarenko
}

UDC 547.972

We have investigated the leaves of Evonymus japonicus (evergreen euonymus) collected in the environs of Sochi. The dry comminuted raw material was exhaustively extracted with $70 \%$ ethanol in the boiling water bath. The evaporated extract was purified repeatedly by treatment with chloroform and ether. Paper chromatography showed that it contained not less than six flavonoids.

The extract was deposited on a column of Kapron and was eluted with $50 \%$ ethanol. The fractions of the third zone, on evaporation, gave a residue consisting of two glycosides: (I) and (II). They were separated by precipitation with lead acetate. The lead complexes were decomposed with $30 \% \mathrm{H}_{2} \mathrm{SO}_{4}$ and $\mathrm{H}_{2} \mathrm{~S}$. The glycosides were recrystallized from aqueous ethanol.

Glycoside (I), with $\mathrm{R}_{f} 0.64$ [system 1: butan-1-ol $-\mathrm{CH}_{3} \mathrm{COOH}-\mathrm{H}_{2} \mathrm{O}(4: 1: 5)$ ] and 0.65 (system 2: $2 \%$ $\mathrm{CH}_{3} \mathrm{COOH}$ ) formed light yellow crystals soluble in water, methanol, and ethanol, and insoluble in ether and chloroform. UV spectrum of (I): $\lambda_{\max } 356,265 \mathrm{~nm}\left(\mathrm{C}_{2} \mathrm{H}_{5} \mathrm{OH}\right)$. On the basis of the bathochromic shifts of the long-wave maximum in the presence of complex-forming and ionizing reagents it was established that the hydroxyls at $\mathrm{C}_{5}$ and $\mathrm{C}_{4}$ are free and those at $\mathrm{C}_{3}$ and $\mathrm{C}_{7}$ have substituents. Enzymatic and acid $(1 \%$ $\mathrm{H}_{2} \mathrm{SO}_{4}, 40 \mathrm{~min}$ in the boiling water bath) hydrolyses gave equimolecular amounts of kaempferol, D-glucose, and L-rhamnose. On partial hydrolysis $\left(0.5 \% \mathrm{H}_{2} \mathrm{SO}_{4}, 5 \mathrm{~min}\right.$ ) glucose and a glycoside (Ia) were detected among the hydrolysis products. Glycoside (Ia) was extracted with ether and purified on Kapron. It had mp $233-236^{\circ} \mathrm{C}, \mathrm{R}_{f} 0.70(1)$ and $0.14(2)$ and formed light yellow plates. Its UV spectrum $\left(\lambda_{\max } 365,265\right)$ showed that there is a substituent at $\mathrm{C}_{7}$. Hydrolysis formed kaempferol and rhamnose.

Glycoside (II), with $\mathrm{mp} 186-184^{\circ} \mathrm{C}, * \mathrm{R}_{f} 0.48$ (1) and 0.56 (2) formed light-green prisms soluble in water and ethanol, and insoluble in chloroform and ether. UV spectrum of (II): $\lambda_{\max } 360,257 \mathrm{~nm}\left(\mathrm{C}_{2} \mathrm{H}_{5} \mathrm{OH}\right)$. Acid hydrolysis gave quercetin, D-glucose, and L-rhamnose in equimolecular amounts. On partial hydrolysis, L-rhamnose and a glycoside (IIa) were found among the products. The glycoside (IIa) had $\mathrm{mp} 221-223^{\circ} \mathrm{C}$, $\mathrm{R}_{f} 0.60$ (1) and 0.31 (2) and formed greenish yellow crystals with $\lambda_{\max } 351,257 \mathrm{~nm}$. Hydrolysis gave quercetin and D-glucose. The UV spectrum shows that the glucose is attached at $C_{3}$. On the basis of the facts presented, enzymatic hydrolysis, and IR spectra, we consider that glycoside (I) is kaempferol 3-O- $\beta-\mathrm{D}-$ glucoside $7-\mathrm{O}-\beta-\mathrm{L}-\mathrm{rhamnoside}$, and (II) is quercetin $3-\mathrm{O}-\beta-\mathrm{D}$-glucoside $7-\mathrm{O}-\alpha-\mathrm{L}-\mathrm{rhamnoside}$, which have been described in the literature [1]. The flavonoids of Japanese euonymus have not been studied previously.

\section{LIT ERATURE CITED}

1. L. Hörhammer, L. Stich, and H. Wagner, Naturwissenschaften, $\underline{46}, 358$ (1959).

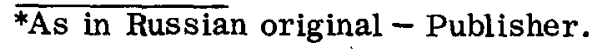

Pyatigorsk Pharmaceutical Institute. Translated from Khimiya Prirodnykh Soedinenii, No. 1, p. 118, January-February, 1972. Original article submitted September 23, 1971.

- 1974 Consultants Bureau, a division of Plenum Publishing Corporation, 227 W'est 17th Street, New York, N. Y. 10011. No part of this publication may be reproduced, stored in a retrieval system, or transmitted, in any form or by any means, electronic, mechanical, photocopying, microfilming, recording or otherwise, without written permission of the publisher. A copy of this article is available from the publisher for $\$ 15.00$. 